Transportation Research Forum

Derivation of Crop Residue Feedstock Supply Curves Using Geographic Information Systems Author(s): Hayk Khachatryan, Eric L. Jessup, and Ken Casavant

Source: Journal of the Transportation Research Forum, Vol. 48, No. 1 (Spring 2009), pp. 5-21

Published by: Transportation Research Forum

Stable URL: http://www.trforum.org/journal

The Transportation Research Forum, founded in 1958, is an independent, nonprofit organization of transportation professionals who conduct, use, and benefit from research. Its purpose is to provide an impartial meeting ground for carriers, shippers, government officials, consultants, university researchers, suppliers, and others seeking exchange of information and ideas related to both passenger and freight transportation. More information on the Transportation Research Forum can be found on the Web at www.trforum.org. 


\title{
Derivation of Crop Residue Feedstock Supply Curves Using Geographic Information Systems
}

\author{
by Hayk Khachatryan, Eric L. Jessup, and Ken Casavant
}

This paper reports on the availability, collection and transportation costs of agricultural crop residue for cellulosic ethanol processing in the state of Washington using Geographic Information Systems. The GIS Network Analyst extension toolset is employed to map and spatially analyze the crop residue available within given distances/haul zones for 12 eastern counties. Using census feature classification codes, driving speed limits were assigned to all road segments to calculate haul times to a specific biorefinery location. The feedstock farm gate cost, transportation costs, resource availability and geographic distribution were incorporated to derive feedstock supply curves. To better understand how variation in transportation costs affects the feedstock delivered costs, a sensitivity analysis is conducted incorporating a range of diesel prices.

\section{INTRODUCTION}

Recently, the growing interest in renewable fuels, such as ethanol or biodiesel, has become a primary concern underlying U.S. national energy security and economic stability. Over many years of moderate use one biofuel, ethanol, has recently gained significant attention as the thrust of renewable fuels to reduce dependency on foreign oil, among a wide range of other issues. The federal government has initiated numerous programs to support and promote processing and use of biofuels to replace gasoline in expectation of significant energy savings (U.S. Government Accountability Office 2007). However, a large disparity exists among the current research-based recommendations regarding economic cost-benefit analyses for processing corn-based ethanol. A significant portion of prior research efforts have identified negative net energy balances from corn-based ethanol due to fossil fuel energy usage for its processing and distribution purposes (McCormick et al. 2003). One of the possible reasons for the disparity in research conclusions is due to different modes of transportation, and thus, different costs influencing total delivered costs. Additionally, regionspecific road infrastructure and varying spatial features of data, such as geographic distribution of feedstocks, can contribute to the different research conclusions.

Given the increasing price of corn (USDA 2007) and the mandated adoption of ethanol, the consideration of other cellulosic materials, including corn stover, wheat straw, wood chips, switchgrass, and poplar, becomes important. In addition to numerous environmental benefits, the main advantages of cellulosic ethanol processing include feedstock resource abundance, higher energy returns (for several dedicated feedstocks) and competitive processing costs (McLaughlin et al. 2002). However, in addition to current technological challenges of cellulosic feedstock processing, there are other major issues to be investigated, such as the delivered cost of feedstocks that may significantly influence the delivered cost of the final product.

The primary objective of this paper is to spatially analyze the collection and transportation costs of cellulosic ethanol feedstock using a Geographic Information System (GIS). This information is then utilized to improve the overall understanding of the economic feasibility of ethanol production in Washington State. Among nine potential biomass sources, this paper considers the agricultural crop residue category. The study area is comprised of 12 counties that produce $93.5 \%$ of the state's agricultural crop residues. ${ }^{1}$ Both the collection and transportation costs are incorporated for calculation of the delivered costs of the feedstocks. A GIS Network Analyst extension (a GIS ArcMap software extension that enables network-based georeferenced data analyses) is utilized to investigate geographically varying crop residue availability within given distances of the 
12-county study area. Using census feature classification codes (CFCC), ${ }^{2}$ driving speed limits were assigned to all segments in the GIS roads shapefile ${ }^{3}$ to calculate haul times for a specific biorefinery location in the study area. Assuming truck transportation, six haul time categories with 30-minute (up to three hour haul time) intervals were used to estimate feedstock availability within each county and each haul time area. Further, the farm gate cost, transportation costs, including loading and unloading, physical availability and geographic distribution information (accounting for site-specific road infrastructure) were combined to derive feedstock supply curves. ${ }^{4}$

\section{LITERATURE REVIEW}

\section{Non-GIS Studies}

Research papers investigating economic feasibility of cellulosic feedstock transportation involve both spreadsheet- and GIS-based models. Sokhansanj et al. (2006) developed a spreadsheet-based model that incorporates weather conditions to calculate corn stover collection costs using a baling system. Consisting of a four-step operation, including combining, shredding, baling and stacking, the overall cost of the stover collection was found to be $\$ 23.27$ per dry ton. Assuming flatbed trailers carrying about 36 rectangular bales, and front-end loaders equipped with special bale grabbers for loading/unloading and stacking the bales, the model simulation calculated $\$ 35.76$ transportation cost for haul distances ranging from 32 to 160 kilometers.

Sokhansanj and Fenton (2006) developed a dynamic model to simulate collection and transportation costs for crop residues and switchgrass, incorporating four different collection options. They found baling is the most common option for the dry form switchgrass collection. A procedure for the crop residue collection slightly differs, since a combine is processing most of the straw. However, in the case of corn the majority of the corn stalk is left, which is then shredded and ready for baling. More details on collecting and stacking wheat straw and corn stover are available in that report. Other factors affecting the size and mode of transportation include the maximum volume and frequency of biomass supply to a biorefinery, the density of biomass, proximity to the biorefinery and the transportation infrastructure between biomass sources and processing plants. They found that the biggest impact on the transportation mode decision is the physical form and quality of biomass.

Kumar and Sokhansanj (2007) used the previously developed spreadsheet-based method (Sokhansanj et al. 2006) to model three biomass collection and transportation systems for switchgrass. Delivered costs to a biorefinery with the capacity of 1,841 dry tons per day totaled $\$ 44-\$ 47$ per dry ton for both round and square bales. Loafing, chopping-pilling, chopping-ensiling methods resulted in $\$ 37, \$ 40$ and $\$ 48$ per dry ton respectively. Collection, transportation (for fixed and variable distances), and delivered costs of several cellulosic feedstocks are summarized in Tables 1, 2 and 3 of the Appendix. Comparable results ( $\$ 40$ per dry ton) for the switchgrass farm gate costs were found in McLaughlin et al. (2002). The paper emphasized the importance of ethanol processing and feedstock production related research in an effort to make the cellulosic ethanol processing operational and commercially successful. According to the authors, switchgrass is economically feasible feedstock and will significantly contribute to biofuel industry advancements.

Sokhansanj and Turhollow (2002) examined two systems and calculated corn stover collection baseline costs. Assuming a fully mechanized bale collection and transport system, and a five-mile distance to the field storage, costs for collecting corn stover residue totaled $\$ 19.70$ and $\$ 21.40$ per dry ton for round and rectangular baling, respectively. The difference in cost was explained by the additional operation and higher equipment cost for the rectangular baling system.

In another research paper, Atchison and Hettenhaus (2003) introduced innovative methods for derivation of collection, storage and transportation costs of corn stover. To account for collection delays, feedstock drying and densification methods were investigated, which were found to increase collection costs from $\$ 35$ to approximately $\$ 50$ per dry ton. In comparison with baling, the one- 
pass harvest method resulted in significant cost reductions. Depending on the yield, net returns to a farmer were $\$ 22-\$ 47$ per acre, while baling totaled $\$ 16-\$ 22$ per acre for the same collection area. Comparing rail and truck efficiencies, the authors emphasized the limitations of rail depending on local situations/constraints. However, if the feedstock supply area is economically expanded (up to a 300 mile distance) by locating additional collection sites, the collection costs using the rail option were found to be in the $\$ 3$ to $\$ 10$ per dry ton range, compared to more than $\$ 15$ per dry ton for the trucking option.

Perlack and Turhollow (2002) investigated the logistics of four different methods to estimate collection, handling, and transporting costs of corn stover to a biorefinery. The authors assumed conventional equipment for baling, and trucks and flatbed trailers for the transportation of collected stover to storage. Large round and large rectangular baling methods resulted in \$44-\$49 per dry ton for collection, storage and haulage, including procurement costs (see comparisons in Tables 1, 2 and 3 of the Appendix).

Another research paper (Graham et al. 1997) summarized nationwide county-level energy crop yields, acreage of land suitable for energy crops, and farm gate cost predictions from the Oak Ridge Energy Crop County Level (ORECCL) database. The average farm gate cost for a short rotation woody crop production in the state of Washington was predicted to be $\$ 86.13$ per dry ton, which emphasizes the aforementioned variation in research conclusions.

Jenkins et al. (2000) used surveys and time-and-motion studies to evaluate the performance and economics of rice straw harvest, transport, and storage systems for industrial applications. Analyzing three types of bales, it was found that total harvest costs range from $\$ 7.50$ to $\$ 42.79$ per ton of rice straw. The large bales had an average total harvest cost of $\$ 12.77$ per ton. Transportation costs for the large bales on trucks (assuming19-ton payload) were estimated at $\$ 9.10$ per ton for a 32 $\mathrm{km}$ one-way haul distance. This cost was disaggregated into loading and unloading cost accounting for $\$ 4.58$ per ton and a distance dependent cost of $\$ 0.14$ per-ton-kilometer.

Perlack and Turhollow (2003) introduced an economic-engineering assessment of corn stover harvesting and transportation for 500 to 4,000 tons per day capacity ethanol processing facilities. The study considered fast tractors transferring large bales of corn stover from fields to storage, which then were hauled to a biorefinery using a flatbed trailer carrying about 30 large bales. Differences in feedstock costs for biorefineries of varying capacity were analyzed. Delivery distances were calculated using a straight line method from field to biorefinery with a road winding factor. As a result, the delivered cost of stover increased from $\$ 44.80$ to $\$ 53.70$ per ton for the 500 and 4,000 tons per day capacity biorefineries, respectively.

Many of these earlier studies estimated the amount of feedstock availability within a given straight-line radius around biorefineries, failing to consider the actual highway distance and speed in determining feedstock availability. Factors that affect economics of biofuels processing, including weather, proximity of feedstock collection area to a biorefinery and road infrastructure, differ from one geographic region to another. Therefore, a more precise economic evaluation of biomass resources and transportation cost calculations should account for varying costs with hauling distances and local transportation infrastructure.

\section{GIS Studies}

Studies involving GIS allow evaluation of cost calculations over geographical areas and modeling of the spatial variation of transportation costs (using different haul times). Graham et al. (1996) developed a GIS-based modeling system to identify potential and optimal bioenergy feedstock locations. This system was designed to model the supply cost of feedstock (energy crops), taking into account spatial variation of resources. The authors adopted an interdisciplinary approach involving information on land use, soil quality, climate and highway networks, as well as environmental and economic models to determine the marginal cost of feedstock supply from potential locations where energy crops might be grown. As a first step of the four-component modeling, the study mapped 
the availability of energy cropland in the study area. In the next step, expected yield and the farm gate cost of the energy crops were defined. Further, the potential farm gate feedstock supply was identified, and the marginal cost of delivery was mapped to the biorefinery destinations. As a last component, the study mapped and ranked the potential biorefinery locations in the study area based on feedstock delivery costs.

Graham et al. (2000) and Zhan et al. (2005) introduced another GIS approach to map the delivered cost surface for a study area that accounted for spatial variation of the factors affecting collection and transportation costs. The study also identified least-cost locations for collecting and transporting biomass to processing plants.

Another study involving GIS (Noon et al. 1996) extended and applied a GIS-based modeling system to forecast the most promising areas for biofuel processing plants in a specific region. Results revealed considerable correlation between variation of switchgrass costs (throughout the study area) and biorefinery plant sizing, as well as facility location decisions. Considering consistent construction and labor costs across the study area, the authors found that the delivery cost of the feedstock is the main determinant in the variable cost of the ethanol processing.

Langholtz et al. (2007) conducted a woody biomass feasibility study for 27 counties in southeastern U.S. states. Detailed explanations were provided about the utilization of the GIS Network Analyst tool to assess the economic feasibility of the woody biomass available in the study area. Taking into account the spatial distribution and variability of the biomass resources, transportation costs were combined with the procurement costs in order to derive the delivered costs.

\section{FEEDSTOCK AVAILABILITY IN WASHINGTON STATE}

GIS data obtained from the National Renewable Energy Laboratory (NREL) identified forest and crop residue, urban wood, primary and secondary mill residues, and methane emissions from landfills as the primary sources of biomass in the state. Using 75 gallons per dry ton biomass-toethanol conversion rate, ${ }^{5}$ NREL (2007) data show that only the agricultural crop residue category ( $20 \%$ of the state's total biomass) could support up to 130 million gallons per year (MGY) of ethanol processing. According to another biomass inventory assessment report, Frear et al. (2005), Washington's biomass is underutilized by 16.9 million annual tons.

The geographic distribution of agricultural crop residue in the state of Washington in relation to the state highway network (using NREL (2007) biomass data) is indicated in Figure 1. The southeast region produces about $94 \%$ of the state's agricultural crop residues, which could support ethanol processing equivalent to $122 \mathrm{MGY}$ (using 75 gallons per dry ton biomass-to-ethanol conversion rate). However, because of increasing transportation (distance dependent) costs, all of the available residue cannot be utilized at the same expense, emphasizing the importance of the decisions pertaining to the optimal location of processing facilities. Another factor that may significantly influence economic vitality (through high transportation costs) of cellulosic ethanol processing is the proximity to ethanol demand markets.

For this particular feedstock, besides the transportation cost component (for both the feedstocks and the final product), there are issues concerning soil fertility after the crop is harvested. Depending on feedstock type, the required quantity of the biomass (crop residue in this case) to be left on the field may adversely impact the delivered costs. By assessing county-level availability of wheat straw, and the economics of ethanol processing in the state of Washington, Kerstetter and Lyons (2001) used a five-year average of crop yields to develop biomass supply curves for a hypothetical biorefinery location. Considering a 20 MGY capacity ethanol facility, the study found that the price of the delivered straw is highly sensitive to the amount of straw left on the ground to assure soil fertility and sustainable crop production. The amount of residue that needs to be left on the field for soil fertility controls may differ according to soil type, crop type and region-specific weather conditions. To be consistent with these requirements, the available crop residue for collection as a 
feedstock (depicted in Figure 1) for cellulosic ethanol processing is based on only $35 \%$ of the total (Milbrandt 2005).

Figure 1: Geographic Distribution of Crop Residue in Relation to the Road Network

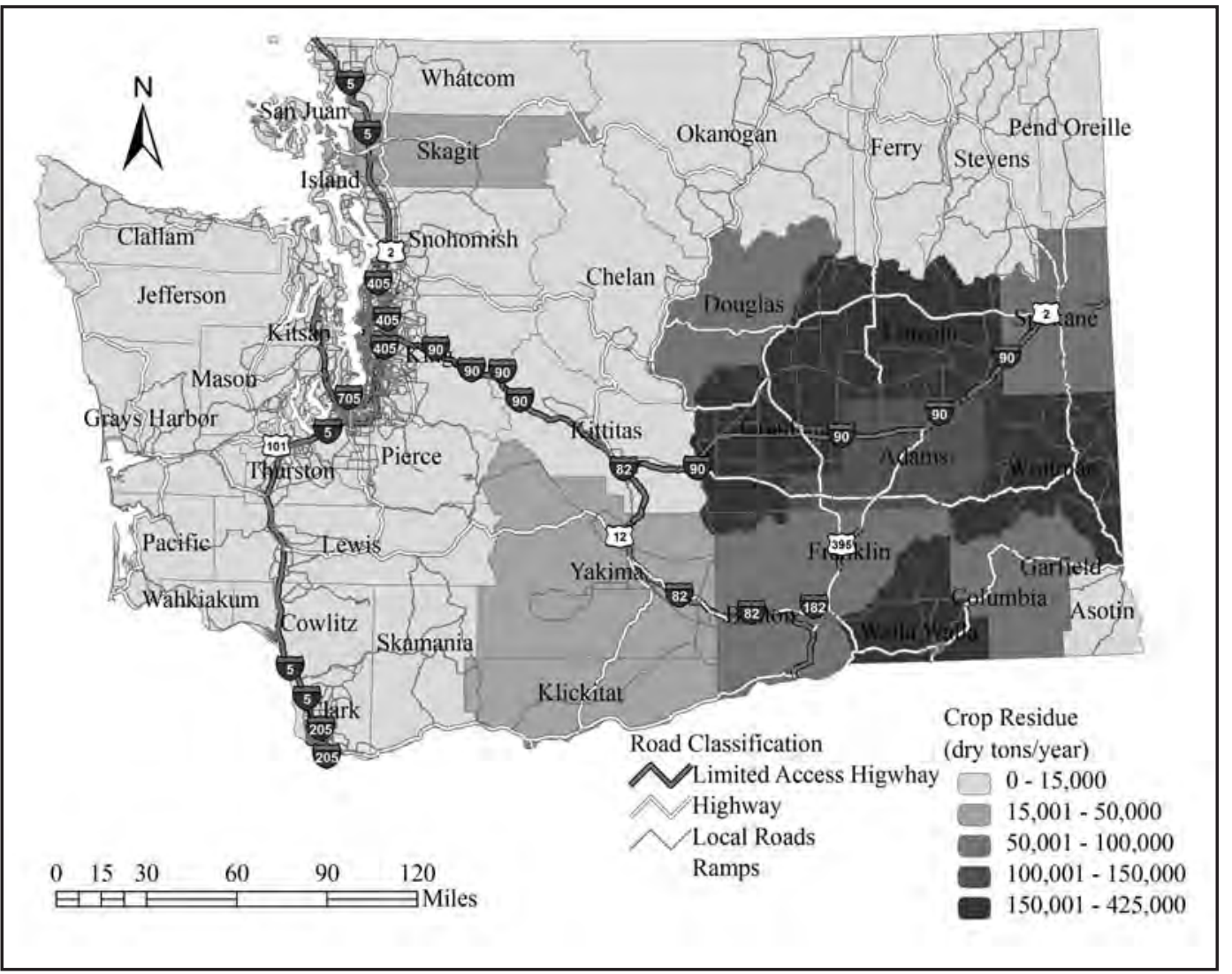

\section{DELIVERED FEEDSTOCK COST COMPONENTS}

\section{Feedstock Procurement Prices}

Analysis of the delivered costs requires information on both the farm gate cost of feedstocks and trucking costs. The delivered cost of crop residue contains procurement, collection and transportation cost components. The collection part in turn, is a function of several considerations, including resource availability, equipment used, collection methods, requirements to maintain the soil fertility (i.e. how much straw needs to be left on the ground) and landscape (slope) of the collection area. The transportation component consists of loading, unloading, transportation to field storage facility (if applicable) and transportation to ethanol conversion facility.

Similar to the collection and transportation components, previous literature suggests a range of procurement prices. One method to determine the amount that the processing plants can "afford" to pay for procurement is to start with the market price of the ethanol. After discounting for the processing, transportation, collection and storage expenses and a profit margin, the remainder is what can be paid as a feedstock procurement fee. Given the geographic distribution of the crop residue, one would expect an increase in the marginal delivered cost, as the quantity demanded increases, since the hauling distances become longer. Plants with large processing capacities (i.e. with large feedstock demand), which translates into longer-distance transportation, may adversely affect the delivered cost of the feedstock. ${ }^{6}$ 
The estimates from recent studies $(1995$ - 2007) provided the base for the feedstock farm gate costs. As mentioned earlier, there is a wide disparity in previous research recommendations on the feedstock supply system cost components. In the collection component, the variation depends on collection methods, equipment used or plant capacity assumptions. Generally comprised of combining, shredding, baling and stacking operations, collections costs vary from $\$ 14$ to $\$ 27$ per dry ton of feedstock. Based on the dispersion of recent research findings/estimations that specifically focused on crop residue farm gate costs, this analysis incorporated varying farm gate costs ranging from $\$ 20$ to $\$ 30$ per dry ton for the transportation cost analysis.

\section{Truck Transportation Costs}

The modal choice of transportation for a specific ethanol plant depends on numerous factors, including (among others) alternative (rail/barge) mode accessibility, proximity of feedstock sources to biorefineries, form and condition of feedstocks, the distance between blending terminals to ethanol fueling stations, size of the payload and traffic congestion. Combined with service attributes that involve speed, availability, consistency/delivery time, loss/damage and flexibility, truck transportation is by far the most flexible option for feedstock transportation. For the purposes of this paper, only truck transportation was considered.

The per ton mile transportation cost of feedstock to biorefineries was derived by combining fixed and variable cost components for truck and trailer, as well as fixed trucking business costs (Khachatryan et al. 2008). Further, the per ton mile transportation costs (including sensitivity analysis) have been combined with the range of feedstock farm gate costs and different haul distances to derive the delivered feedstock costs. Fixed cost calculations require information on the interest rate, the life span of equipment (trucks in this case), ownership, equipment purchase price and expected salvage value, as well as information on insurance and license fees. Variable costs involve repair and maintenance, tire, fuel and labor costs. Trucking costs are strongly sensitive to fuel prices, accounting for about $46 \%$ of the per ton mile costs. Increasing diesel prices influence not only the feedstock transportation costs, but also the distribution segment of the transportation cost chain. In comparison with the Apr-07 through Oct-07 segment depicted in Figure 2, where diesel prices are in a stable range, the trucking costs significantly increase as diesel prices rose sharply in the Jan-08 to Jun-08 period.

To measure the effect of the increasing fuel prices on trucking costs that influence the delivered cost of feedstocks, a sensitivity analysis was conducted and is discussed in the results section. ${ }^{7}$

\section{GIS DATA AND METHODOLOGY}

As mentioned earlier, the delivered cost of feedstocks is not fixed, because procurement costs differ by collection methods, and transportation rates differ by truck configuration, fuel price and distance/ time traveled, among others. Since processing plant capacity changes the above mentioned factors, the feedstock costs will differ accordingly. These relationships are interactive, which makes it uncertain whether the large processing plants with large capacities will necessarily benefit from the traditional economies of scale. The derivation of feedstock supply curves using GIS methodology addresses this issue by taking into account the feedstock resource availability within certain geographic areas around biorefineries.

The transportation costs were calculated by incorporating spatial attributes of the road infrastructure. Many studies reviewed in the literature section considered straight-line distances from the biorefinery, neglecting local road infrastructure details. In order for the economic evaluation of biomass resources to be accurate, spatially varying availability, hauling distances, driving speed limits, trucking costs and collection cost information need to be spatially integrated. Because transportation costs tend to increase with longer distances, in some situations it may be feasible to use relatively costly feedstock that is available within close distances of the plant, rather 
Figure 2: Trucking Cost Sensitivity to U.S. Diesel Retail Sales Prices

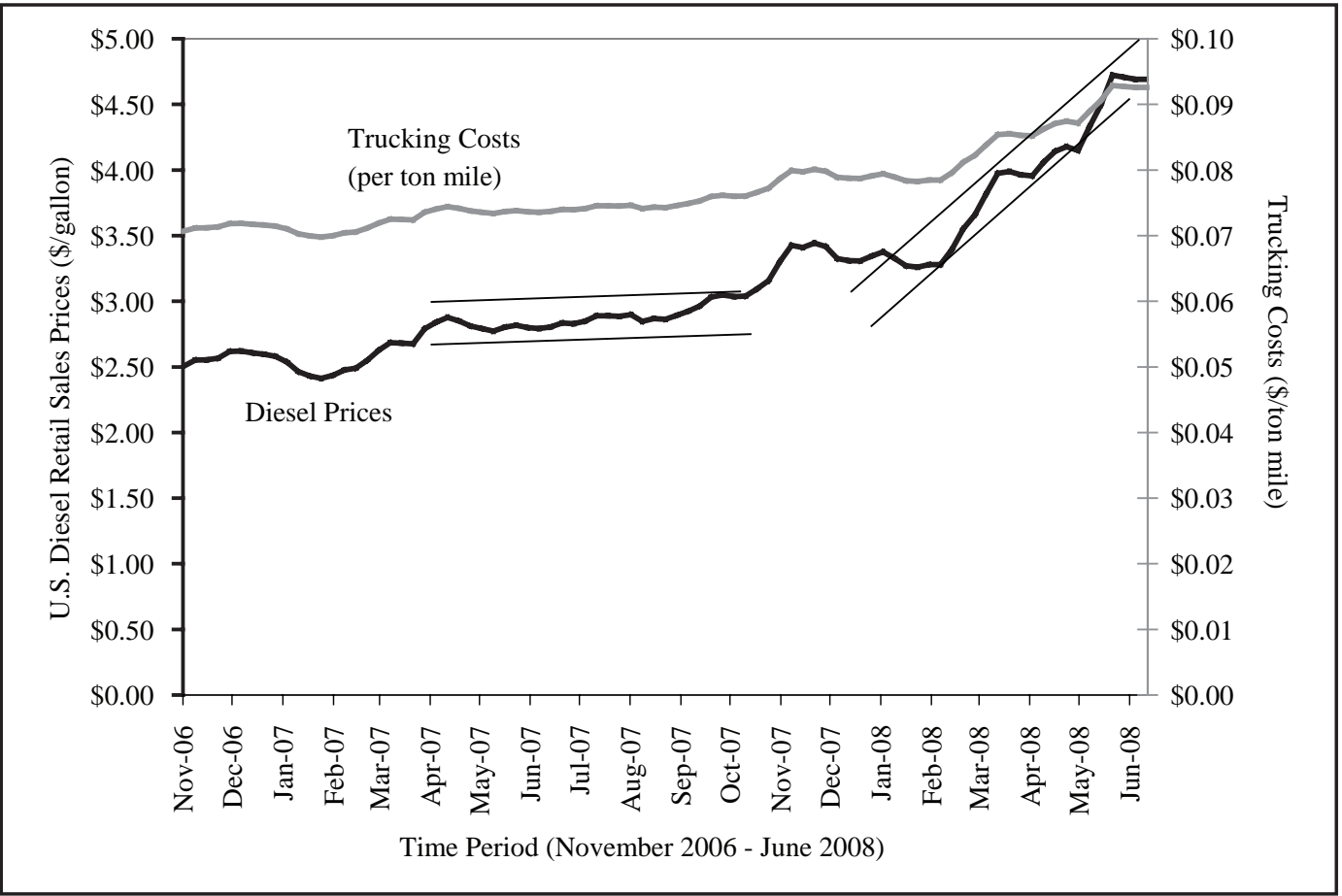

Data Source: Diesel prices were obtained from EIA (2008).

than hauling cheaper feedstock longer distance. Therefore, this analysis integrates spatially varying distribution with the feedstock recovery costs and site-specific road infrastructure.

The transportation cost procedures started with querying out counties in the study area from the state of Washington biomass shapefile obtained from the NREL GIS Data and Analysis Tools website (NREL 2007). Biomass shapefiles represent a data layer where counties are depicted as polygons with attribute information such as area, boundaries, population, etc., and spatial information such as latitude, longitude and projection. ${ }^{8}$ U.S. Census Topologically Integrated Geographic Encoding and Referencing (TIGER) road shapefiles for the study area counties were obtained through the Environmental Systems Research Institute (ESRI 2000) website. Census feature classification codes were then joined to the roads shapefile attributes table to assign speed limits to each of the road segments, allowing travel times (in minutes) for each road segment to be calculated:

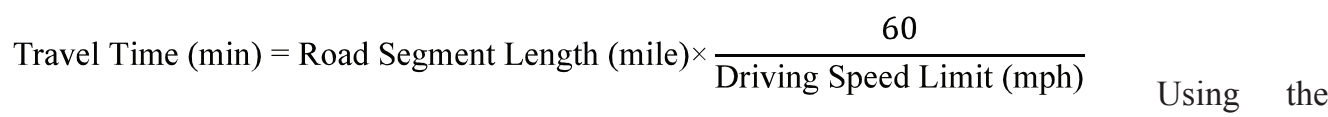

GIS Network Analyst extension, the road shapefile was converted into a network dataset. The Network Analyst extension enables network-based spatial analysis, such as finding the closest facility from a particular location, identifying routes, finding driving directions and mapping service areas based on distance and/or travel time from/to specific locations. Using Network Analysis extension Service Area toolset, layers as shown in Figure 3 were mapped. The geographic location of the cellulosic ethanol processing plant that is currently in the planning stage is in the central part of the study area (Lyons 2008). To keep the map simple, the road layer was made visible only in the 0-30 minute haul zone.

In order to identify the feedstock resource availability within increasing driving distances around the ethanol processing plant, the service areas cover the entire study area at 30-minute 
increments (Figure 3). For instance, within the 30-minute buffer zone, all available feedstocks will require a 30-minute haul time (maximum) to be transported from the field to the processing plant. The cost attribute for service areas generation was set as travel time in minutes, and the proposed ethanol facility location has been identified as a point where the feedstock needs to be hauled. ${ }^{9}$

After the generation of service areas (depicted in Figure 3), the resulting distance-based layers were joined with the biomass layer, so that for each service area the available agricultural crop residue in annual tons is identified at the county level. Further, per ton mile transportation costs, considering loading/unloading delays, physical availability and geographic distribution, were spatially integrated to derive the transportation costs (per dry ton) of feedstocks. Based on this information, the feedstock supply curves were constructed by processing plant capacity.

Figure 3: Service Areas by Haul Times with Highlighted Roads within 30-Minute Intervals

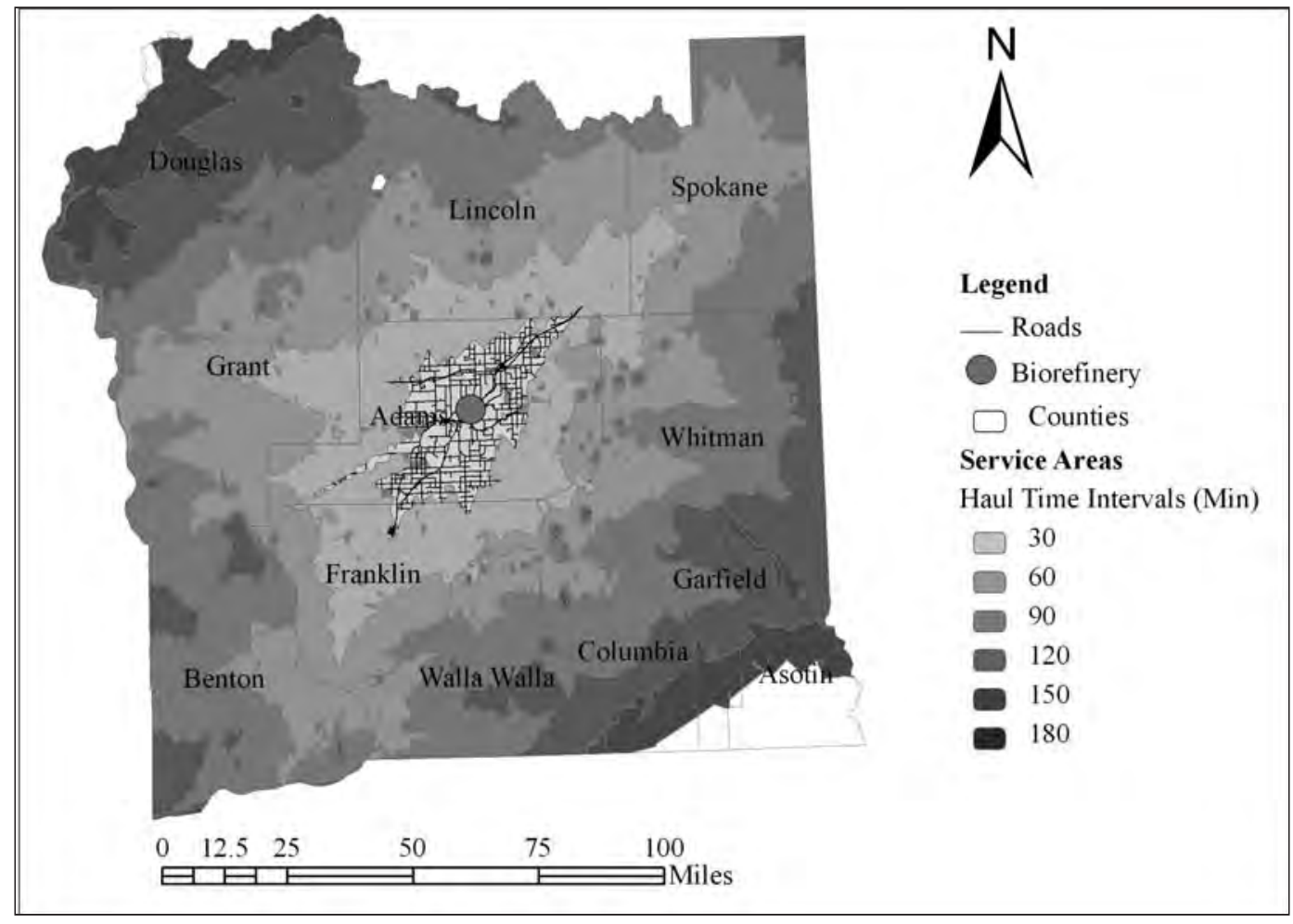

\section{RESULTS}

The attribute table of the resulting GIS data layer (that includes feedstock and haul zone information) was summarized by haul distances and exported to a spreadsheet, allowing identification of the amount of feedstock available in each haul zone at the county level. Given data limitations, in order to construct resource availability curves using haul zone proportions, a key assumption is required and used - a homogenous distribution of the biomass within each county in the study area. Figure 4 depicts resulting crop residue availability by haul time and by county in the study area.

The availability curves can be expressed in two ways. In Figure 4, the amount of feedstock in each haul zone is shown as the amount available only in that zone. Alternatively, the cumulative availability of crop residue in the study area can be depicted, such that increasing haul time results in increasing availability of feedstocks. 
Figure 4: Crops Residue Biomass Availability by Haul Times (from a Biorefinery) for the Counties in the Study Area

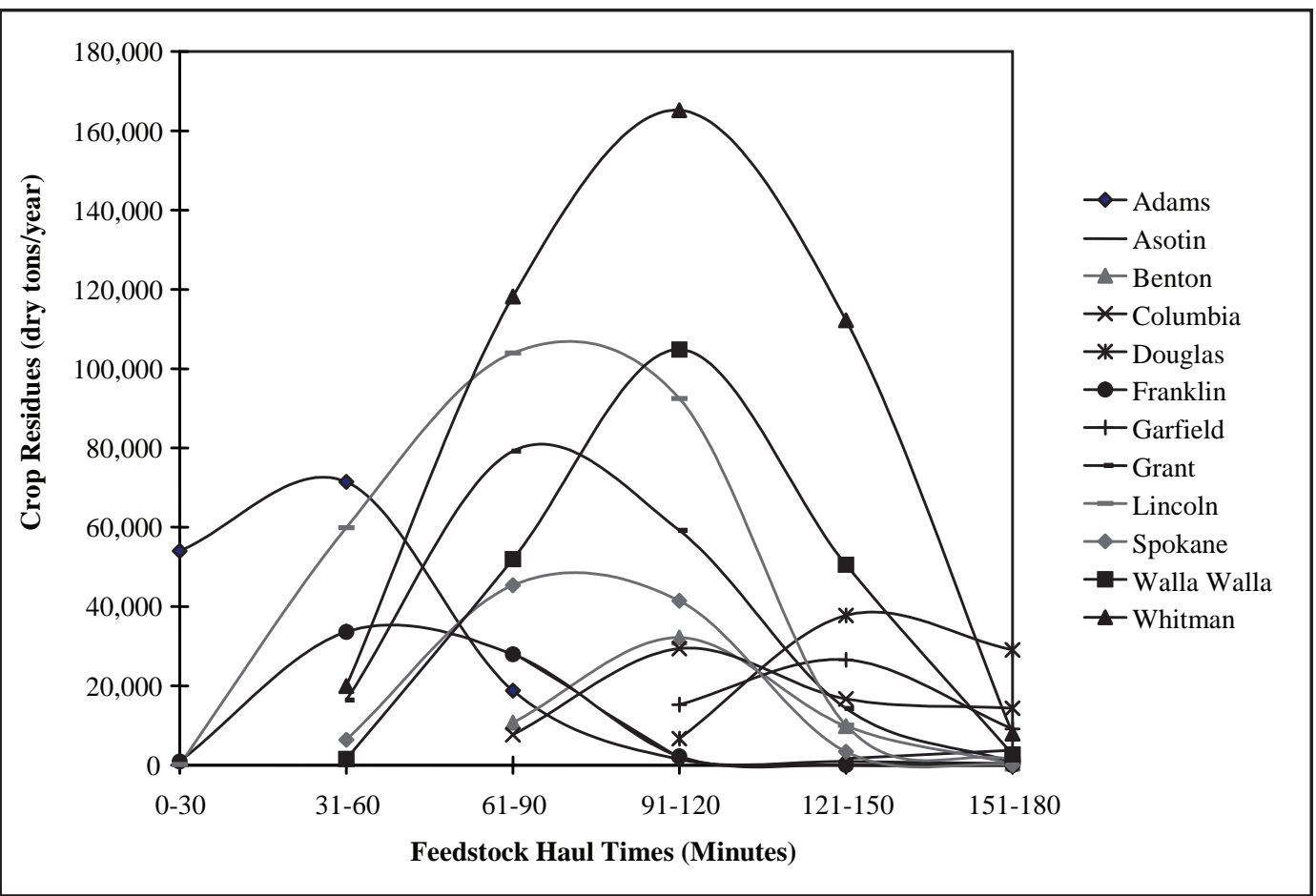

Depending on the specific objective, both methods of expressing feedstock availability can be useful. Suppose a processing plant can currently "afford" to haul feedstocks from at most two hours of drive time from their location. If, for instance, the processing facility operations management is interested in knowing the amount of feedstock that is available within the next $\left(3^{\text {rd }}\right)$ hour of drive time, then the representation form in Figure 4 will be more useful. In other words, given the geographic distribution of feedstock, by driving one more hour (to reach more distant areas), Figure 4 shows the resource availability specifically in that new zone. If additional expenses from driving one more hour are considered, the figure can inform the cost of those additional feedstocks.

As shown in Figure 4, the biomass availability sharply increases starting from the 31-60-minute haul zone and reaches its highest levels of availability at the 61-90-minute zone for counties Grant, Lincoln and Spokane. Adams and Franklin counties reach their highest levels within the 31-60minute interval. The availability in the counties Whitman, Walla Walla, Benton and Columbia peaks within the 91-120-minute haul zone. Finally, the availability in the Douglas and Garfield counties starts within the 91-120-minute haul zone and reaches its highest level within the 121-150-minute haul zone.

On the other hand, if the plant operations management is interested in knowing the total supply of the feedstock within certain haul times, Figure 5 will be more useful since it shows cumulative availability of feedstocks. In Figure 5, counties Adams, Lincoln and Whitman reach their maximum cumulative availability within 90,130 and 160 minutes of drive time respectively. In comparison, feedstocks to be transported from counties Garfield and Douglas require haul distances starting at 120 miles.

Derivation of feedstock supply curves (Figure 6) involves several components. First, the processing plant capacity that the existing/available feedstock can support was determined using 75 gallons per dry ton biomass-to-ethanol conversion rate. ${ }^{5}$ Another important measure is the resource availability within various haul time zones around the biorefinery. Haul times used for the supply 
Crop Residue Feedstock Supply Curves

Figure 5: Cumulative Crop Residue Biomass Availability by Haul Times (from a Biorefinery) for the Counties in the Study Area

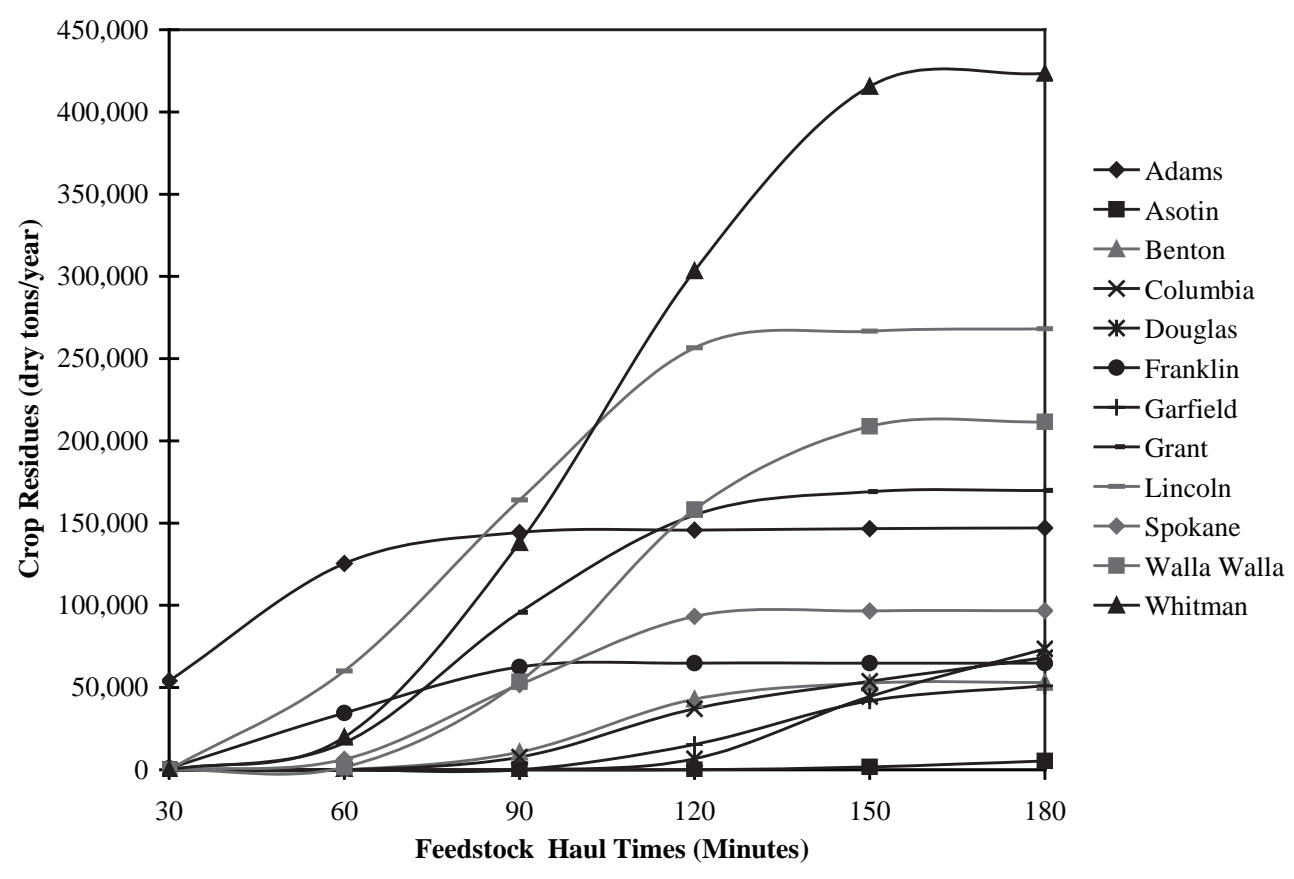

Figure 6: Feedstock Supply Curves Using \$20, \$25 and \$30 per Dry Ton Farm Gate Costs

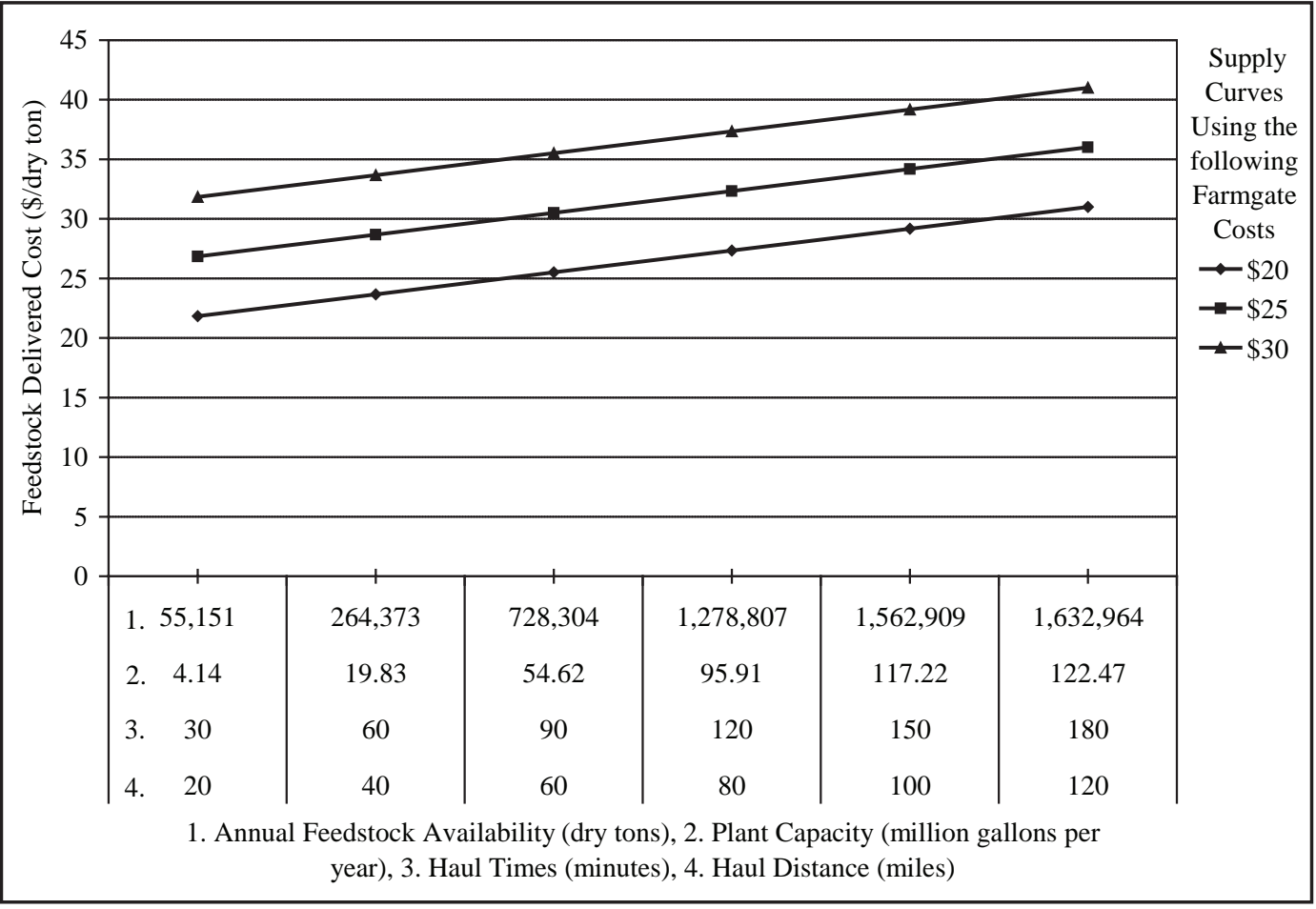


curve construction were adjusted for transportation delays, such as stops, turns and slow speed road segments. The relationships between the delivered cost of a feedstock per dry ton (specifically for the ethanol processing plant depicted in Figure 3) and the annual feedstock availability, processing plant capacity, feedstock haul times (in minutes) and distances (miles) are depicted in Figure 6.

On the horizontal axis, the first line represents the amount of crop residue available within the boundaries of a specific haul zone. The second line shows an incremental plant capacity in million gallons per year that the feedstock (cumulatively) available in a given haul zone can support. The delay-adjusted distance measure is included in order to fine tune the haul times. The slopes of the curves in Figure 6 reveal the magnitude of the positive relationship between increasing haul times or increasing feedstock amount required by larger processing plants and the delivered cost of feedstock for all of the three feedstock farm gate cost scenarios. Depending on the plant's annual processing capacity, supply curves provide information about the delivered cost of feedstock. For example, for the geographic location of the $55 \mathrm{MGY}$ proposed plant (mapped in Figure 3), the delivered cost was found to be $\$ 25.51$ per dry ton, considering feedstock farm gate cost of $\$ 20$. More feedstock, and thus, higher processing capacity (up to $122.47 \mathrm{MGY}$ ) could be supported within the area under investigation by increasing haul distances. However, the delivered cost of feedstock will increase accordingly (\$31.01 per dry ton).

Not only is the delivered cost of feedstock sensitive to the farm gate costs and the haul distances, but they are also sensitive to the diesel prices since the fuel costs constitute about $46 \%$ of the per ton mile transportation costs (as discussed in the Truck Transportation Costs section). A sensitivity analysis with a range of diesel prices, that also incorporated different processing plant capacities, was used to allow for the evaluation of the delivered feedstock costs in relation to the different ethanol processing plant capacities. Diesel prices from November 2007 to June 2008 (EIA 2008) were chosen to analyze the variation of feedstock delivered costs with different farm gate costs $(\$ 20$, \$25 and \$30) and small, medium and large plant capacities (20 MGY, 55 MGY, and $120 \mathrm{MGY}$ ). As shown in Figure 7, small-scale processing plants are comparatively less sensitive to diesel price increases in terms of the delivered feedstock costs for all three farm gate cost scenarios.

Figure 7: Delivered Feedstock Cost Sensitivity to Diesel Prices

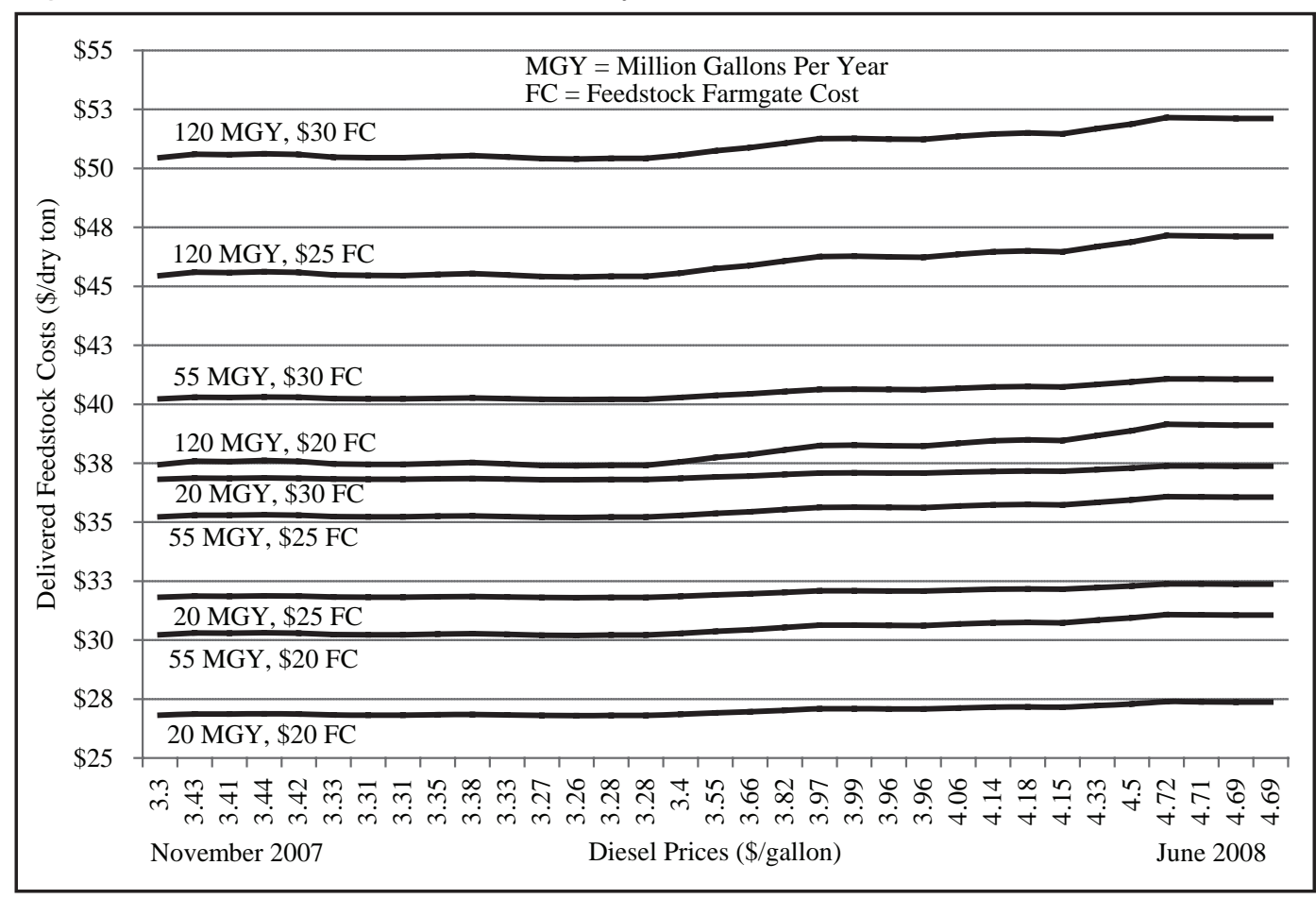


In comparison, the influence of the increasing diesel prices on the delivered feedstock costs for the medium and large processing plants is considerably higher. As a result of increasing diesel prices since January 2008 (39\% increase from January to June), the delivered costs of feedstocks for the 55 MGY plant increased by 3\% considering \$20 farm gate costs, and 2\% considering \$25 and \$30 farm gate costs. Because larger plants involve more transportation activity, the delivered feedstock costs for the $120 \mathrm{MGY}$ capacity plant increased by $4 \%$ considering $\$ 20$ and $\$ 25$ farm gate costs, and $3 \%$ considering $\$ 30$ farm gate costs.

Supply curves constructed using GIS-generated data help in assessing the optimal size of the plant given not only the feedstock availability in the study area, but also the geographic distribution and local road infrastructure. However, to assess the benefits related to economies of scale, processing costs need to be investigated as well. This may partially alter the delivered cost of the final product - ethanol blend.

\section{CONCLUSIONS}

With the growing use and production of ethanol, the ethanol industry has concerns pertaining to transportation issues. Feedstock delivery infrastructure that supports sufficient processing capacity and timely feedstock shipments proves to be an important factor for the sustainable development of the ethanol industry, an industry that will contribute to enhanced national energy security.

The methodology in this paper, modified from Langholtz et al. (2007), effectively reveals the value of spatial relationships when incorporating feedstock availability, resulting in increased accuracy of cost calculations. In addition to haul distances, increasing price of transportation fuel is another component influencing the delivered feedstock costs. This paper contributes to existing literature (Graham et al. 1996, 2000; Zhan et al. 2005; Noon et al. 1996) by analyzing spatially variable feedstock availability in relation to varying processing plant capacities and by incorporating delivered feedstock cost sensitivity to transportation fuel price analysis. However, it is important to mention the weaknesses of this paper, imposed by data limitations. The availability of feedstocks within county boundaries was assumed to be evenly distributed. A consideration of the density of agricultural crop residue production will considerably improve feedstock supply curve calculations, an area that our future research will improve upon.

The underlying theme of this study was to investigate the economic feasibility of cellulosic ethanol processing from agricultural crop residue feedstock by incorporating varying farm gate costs, truck transportation costs, and spatial distribution of feedstocks. Feedstock supply curves suggest that depending on the processing plant capacity and transportation distances, transportation costs may significantly influence the delivered cost of the feedstock. Thus, the economics of large capacity plants may not necessarily be driven by economies of scale as it pertains to the feedstock production, because more capacity requires longer feedstock haul distances. Additionally, the analysis revealed that smaller capacity processing plants are less sensitive to increasing diesel prices in terms of delivered feedstock costs. Given the considerable proportion of total transportation cost attributed to transportation fuel costs, these results may affect optimal processing plant size decisions.

The state of Washington has a number of corn- and cellulose-based ethanol plants under different phases of development. Despite favorable state and federal support for the biofuels industry, it is premature to predict an operational success for both existing corn-based (given corn price increases) and planned cellulosic-based processing plants. In particular, the economic viability of the cellulosic ethanol industry may partially be influenced by one of the main determinants in the variable cost of ethanol processing - the delivered cost of feedstocks. Due to its spatially variable availability, the total biomass that is available in the region cannot be fully utilized at the same expense, especially, as shown, due to the increasing price of diesel fuel.

As an important component of the ethanol processing supply chain, the transportation costs significantly influence the feasibility of the emerging cellulosic ethanol industry through the 
feedstock supply system. To refine the study, further work will be done on identifying the processing and final product distribution costs, which will be combined with the delivered costs of feedstock to derive the delivered cost of ethanol.

\section{APPENDIX}

Table 1: Collection Costs (per dry ton)

\begin{tabular}{|c|c|c|c|c|c|c|}
\hline Author & Feedstock & \multicolumn{5}{|c|}{ Collection Options/Methods } \\
\hline $\begin{array}{l}\text { Kumar and } \\
\text { Sokhansanj } \\
(2007)^{\mathrm{a}}\end{array}$ & Switchgrass & $\begin{array}{c}\text { Square } \\
\text { Bales } \\
\$ 24.10\end{array}$ & $\begin{array}{l}\text { Round } \\
\text { Bales } \\
\$ 22.62\end{array}$ & $\begin{array}{l}\text { Loafing } \\
\$ 13.67\end{array}$ & $\begin{array}{c}\text { Chopping- } \\
\text { Piling } \\
\$ 14.81\end{array}$ & $\begin{array}{c}\text { Chopping- } \\
\text { Ensiling } \\
\$ 22.63\end{array}$ \\
\hline $\begin{array}{l}\text { Sokhansanj et } \\
\text { al.(2006) }\end{array}$ & Stover & \multicolumn{5}{|c|}{$\begin{array}{c}\text { Baling }^{\mathrm{b}} \\
\$ 19.16^{\mathrm{c}}(21.12 \text { \$/ton })\end{array}$} \\
\hline $\begin{array}{l}\text { Sokhansanj and } \\
\text { Fenton (2006) }\end{array}$ & $\begin{array}{c}\text { Switchgrass } \\
\text { and Crop } \\
\text { Residues }\end{array}$ & $\begin{array}{c}\text { Square } \\
\text { Bales } \\
\$ 23.72\end{array}$ & $\begin{array}{l}\text { Loafing } \\
\$ 19.69\end{array}$ & $\begin{array}{c}\text { Chopping } \\
\text { Dry-Pilling } \\
\$ 35.71\end{array}$ & $\begin{array}{r}\text { Choppin } \\
\text { Ens } \\
\$ 35\end{array}$ & $\begin{array}{l}\text { Moist - } \\
\text { ing } \\
12\end{array}$ \\
\hline $\begin{array}{l}\text { Sokhansanj and } \\
\text { Turhollow }(2002)^{\mathrm{d}}\end{array}$ & Corn Stover & \multicolumn{2}{|c|}{$\begin{array}{l}\text { Round Bales } \\
\$ 19.70\end{array}$} & \multicolumn{3}{|c|}{$\begin{array}{c}\text { Rectangular Bales } \\
\$ 21.40\end{array}$} \\
\hline $\begin{array}{c}\text { Perlack and } \\
\text { Turhollow }(2002)^{\mathrm{e}}\end{array}$ & Corn Stover & $\begin{array}{l}\text { Large } \\
\text { Round } \\
\text { Bales } \\
\$ 24.80\end{array}$ & $\begin{array}{c}\text { Large } \\
\text { Rectanguar } \\
\text { Bales } \\
\$ 22.25\end{array}$ & $\begin{array}{l}\text { Unprocessed- } \\
\text { Pickup } \\
\text { High Cost } \\
\$ 26.80\end{array}$ & $\begin{array}{r}\text { Unprocess } \\
\text { Low }\end{array}$ & $\begin{array}{l}\text { d Pickup- } \\
\text { Cost } \\
67\end{array}$ \\
\hline
\end{tabular}

a Calculations did not include production costs such as machinery operations, seeds, fertilizers, lime, herbicides, land charges, reseeding, etc.

${ }^{\mathrm{b}}$ Collection methods were not specified.

c The value was converted from $\$ \mathrm{Mg}^{-1}$ to $\$ /$ ton using 1.102 conversion rate.

${ }^{\mathrm{d}}$ See the paper for additional assumptions.

e Calculations include delivery to a storage facility with 4000 dry tons per day processing capacity. 
Table 2: Transportation Costs (per dry ton)

\begin{tabular}{|c|c|c|c|c|c|c|}
\hline Author & Feedstock & \multicolumn{5}{|c|}{ Collection Options/Methods } \\
\hline $\begin{array}{l}\text { Kumar and } \\
\text { Sokhansanj } \\
(2007)^{\mathrm{a}}\end{array}$ & Switchgrass & $\begin{array}{l}\text { Load bale- } \\
\text { truck } \\
\text { (stationary } \\
\text { grinder) } \\
\$ 21.19\end{array}$ & Bale & r load (ground) & uck & $\begin{array}{c}\text { Ground } \\
\text { biomass } \\
\text { (pile or } \\
\text { silage) - } \\
\text { truck } \\
\$ 25.32\end{array}$ \\
\hline $\begin{array}{l}\text { Sokhansanj et } \\
\text { al. }(2006)^{\mathrm{b}}\end{array}$ & Stover & \multicolumn{5}{|c|}{$\begin{array}{l}\text { Rectangular bale - flatbed trailer } \\
\$ 29.45^{\mathrm{c}}(32.45 \$ / \text { ton })\end{array}$} \\
\hline $\begin{array}{l}\text { Sokhansanj and } \\
\text { Fenton }(2006)^{\mathrm{d}}\end{array}$ & $\begin{array}{l}\text { Switchgrass } \\
\text { and Crop } \\
\text { Residues }\end{array}$ & \multicolumn{2}{|c|}{$\begin{array}{c}\text { Large square bale - flat } \\
\text { bed trailer (variable } \\
\text { distance: } 20-100 \mathrm{~km}) \\
\$ 19.41\end{array}$} & \multicolumn{3}{|c|}{$\begin{array}{l}\text { Large square bale - flat } \\
\text { bed trailer (fixed distance: } \\
\qquad 100 \mathrm{~km})\end{array}$} \\
\hline $\begin{array}{c}\text { Perlack and } \\
\text { Turhollow (2002) }\end{array}$ & Corn Stover & $\begin{array}{l}\text { Large } \\
\text { Round } \\
\text { Bales } \\
\$ 10.06\end{array}$ & $\begin{array}{c}\text { Large } \\
\text { Rectanguar } \\
\text { Bales } \\
\$ 10.62\end{array}$ & $\begin{array}{c}\text { Unprocessed- } \\
\text { Pickup } \\
\text { High Cost } \\
\$ 7.32\end{array}$ & & $\begin{array}{l}\text { Pickup- } \\
\text { Cost }\end{array}$ \\
\hline
\end{tabular}

a The transportation cost includes loading, traveling and unloading expenses and is averaged over a year.

b The transportation cost includes grinding, transporting, loading and unloading.

c The value is converted from $\$ / \mathrm{Mg}$ to $\$ /$ ton using 1.102 conversion rate.

d The transport operations used for the cost calculation include loading, traveling, unloading, stacking and grinding.

e A facility with 4000 dry ton/day processing capacity was considered.

Table 3: Delivered Costs (per dry ton)

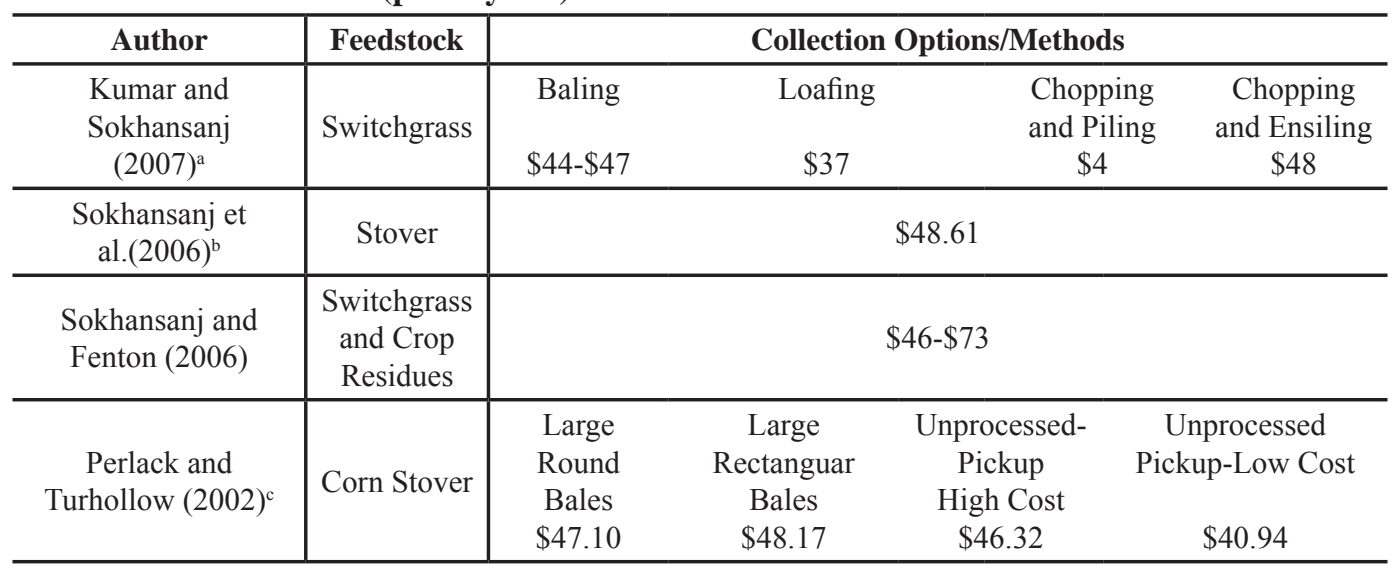

a, b Calculations exclude farming costs and payments to farmers.

c In addition to the collection and transportation costs, calculations include operations expenses and payments to farmers. 


\section{Endnotes}

1. The 12 counties include Adams, Asotin, Benton, Columbia, Douglas, Franklin, Garfield, Grant, Lincoln, Spokane, Walla Walla and Whitman.

2. CFCC provides alphanumeric codes for each line feature to classify roads, railroads, waterways, and any other linear features in the GIS shapefile (a highways shapefile in this case).

3. A shapefile is a name of the file used in Geographic Information Systems that contains nontopological geometry and attribute information for the spatial features (roads in our case) in a data set. Feature information, such as geometry and attributes (i.e., length of the segment, name, location, etc.), is stored as a shape containing a set of vector coordinates.

4. The methodology developed in this paper (with appropriate modifications) will later be applied to the rest of the seven feedstock types.

5. The biomass-to-ethanol conversion rate is based on personal communications with cellulosic ethanol industry experts.

6. This analysis assumes that resource availability depends on the required amount of straw to be left on the ground in order to maintain soil fertility.

7. A sensitivity analysis will further be useful to examine the variation of the delivered cost of not only the feedstocks, but also the final product (ethanol blend) based on fuel price fluctuations.

8. Geographic projection refers to a transformation of a spheroid surface to a flat map while maintaining spatial relationships. The attribute table of the shapefile contains annual availability for crop, forest, primary mill, secondary mill, urban wood residues and switchgrass (in dry tons), and methane emissions from manure management and domestic wastewater treatment (in tons) per county. As indicated earlier, the crop residue category was selected for the analysis in this paper.

9. The reasons for conducting the analysis based on travel time rather than on the distance attribute include varying site-specific road infrastructure, geographical constraints, and varying elevation of the study area. Detailed discussion of this topic is provided in Langholtz et al. (2007).

\section{References}

Atchison, J.E. and J.R. Hettenhaus. Innovative Methods for Corn Stover Collecting, Handling, Storing, and Transporting. Report No. ACO-1-31042-01, Prepared for National Renewable Energy Laboratory, Colorado, 2003.

Energy Information Administration (EIA). Official Energy Statistics from the U.S. Government. Weekly Retail On-Highway Diesel Prices. June, 2008. http://tonto.eia.doe.gov/oog/info/wohdp/ diesel.asp. Accessed May, 2008.

Environmental Systems Research Institute/U.S. Census Bureau. Census 2000 TIGER/Line Data. http://www.esri.com/data/download/census2000_tigerline/index.html. Accessed October, 2007.

Frear, C., B. Zhao, G. Fu, M. Richardson, S. Chen, and M.R. Fuchs. Biomass Inventory and Bioenergy Assessment: An Evaluation of Organic Material Resources for Bioenergy Production in Washington State. Publication No. 05-07-047. Department of Biological Systems Engineering, 
Washington State University, 2005. http://www.ecy.wa.gov/pubs/0507047.pdf. Accessed October, 2007.

Graham, R.L., B.C. English, and C.E. Noon. "A Geographic Information System-based Modeling System for Evaluating the Cost of Delivered Energy Crop Feedstock." Biomass and Bioenergy 18(4), (2000): 309-329.

Graham, R.L., L.J. Allison, and D.A. Becker. "ORECCL - Summary of a National Database on Energy Crop Landbase, Yields, and Costs." Third Biomass Conference of the Americas: Energy, Environment, Agriculture, and Industry, (1997): 205-213.

Graham R.L., B.C. English, C.E. Noon, W. Liu, M.J. Daly, and H.I. Jager. “A Regional-Scale GISBased Modeling System for Evaluating the Potential Cost and Supplies of Biomass from Biomass Crops," Bioenergy '96 Proceedings. Nashville, Tennessee, 1996.

Jenkins, B.M., R. Bakker-Dhaliwal, M.D. Summers, L.G. Bernheim, H. Lee, W. Huisman, and L. Yan. "Equipment Performance, Costs, and Constraints in the Commercial Harvesting of Rice Straw for Industrial Applications.” ASAE Paper No.006035, ASAE, St. Joseph, MI 49085-9659, 2000.

Kerstetter, J.D. and J.K. Lyons. Wheat Straw for Ethanol Production in Washington: A Resource, Technical, and Economic Assessment. Extension Energy Program, Washington State University, 2001. http://www.energy.wsu.edu/documents/renewables/WheatstrawForEthanol.pdf. Accessed October, 2007.

Khachatryan, H., E. Jessup, and K. Casavant. Biomass Inventory Technology and Economics Assessment: Collection and Distribution Cost Curves. Submitted to The Pacific Rim Summit on Industrial Biotechnology and Bioenergy, Vancouver, Canada, 2008.

Kumar, A. and S. Sokhansanj. "Switchgrass (Panicum vigratum, L.) Delivery to a Biorefinery Using Integrated Biomass Supply Analysis and Logistics (IBSAL) Model.” Bioresource Technology 98(5), (2007): 1033-1044.

Langholtz, M., D.R. Carter, A.W. Hodges, J.E. O'Leary, and R. Schroeder. Wood to Energy: Community Economic Profile. Research Reports, School of Forest Resources and Conservation, Florida Cooperative Extension Service, September 2007. http://edis.ifas.ufl.edu/FR216. Accessed November, 2007.

Lyons, K. Biofuel Development in Washington. WSU Extension Energy Program, Washington State University, 2008.

McCormick, M., S. Freifeld, and L. Kiesling. A Federal Ethanol Mandate: Is it Worth It? If Not, Why is It so Popular? Reason Foundation, Policy Studies, 2003. http://www reason.org/ps315.pdf. Accessed October, 2007.

McLaughlin, S.B., D.G. de la Torre Ugarte, C.T. Garten Jr., L.R. Lynd, M.A. Sanderson, V.R. Tolbert, and D.D. Wolf. "High Value Renewable Energy from Prairie Grasses." Environmental Science Technology 36(10), (2002): 2122-2129.

Milbrandt, A. A Geographic Perspective on the Current Biomass Resource Availability in the United States. Technical Report NERL/TP-560-39181, National Renewable Energy Laboratory, December, 2005.

National Renewable Energy Laboratory. The Dynamic Maps, GIS Data and Analysis Tools. 2007. http://www nrel.gov/gis. Accessed September, 2007. 
Noon, C.E., M.J. Daly, R.L. Graham, and F.B. Zhan. "Transportation and Site Location Analysis for Regional Integrated Biomass Assessment (RIBA)." Proceedings of Bioenergy '96. Nashville, Tennessee, 1996.

Perlack, R.D. and A.F. Turhollow. "Feedstock Cost Analysis of Corn Stover Residues for Further Processing." Energy 28(14), (2003): 1395-1403.

Perlack, R.D. and A.F. Turhollow. Assessment of Options for the Collection, Handling, and Transport of Corn Stover. Report no. ORNL/TM-2002/44, Oak Ridge National Laboratory, 2002.

Sokhansanj, S. and A. Turhollow. "Baseline Cost for Corn Stover Collection." Applied Engineering in Agriculture 18(5), 2002: 525-532.

Sokhansanj, S., A. Kumar, and A.F. Turhollow. "Development and Implementation of Integrated Biomass Supply Analysis and Logistics Model (IBSAL)." Biomass and Bioenergy 30(10), (2006): 838-847.

Sokhansanj, S. and J. Fenton. Cost Benefit of Biomass Supply and Pre-processing. Research Integration Program Reports, The BIOCAP Canada Foundation, (2006): 20-24.

USDA. Economic Research Service. Feed Grains Database: Yearbook Tables. http://www.ers.usda. gov/Data/feedgrains/StandardReports/YBtable12 htm. Accessed December, 2007.

U.S. Government Accountability Office, Reports and Testimonies. Biofuels, DOE Lacks a Strategic Approach to Coordinate Increasing Production with Infrastructure Development and Vehicle Needs. Report to Congressional Requesters, June, 2007.

Zhan, F.B., X. Chen, C.E. Noon, and G. Wu. "A GIS-Enabled Comparison of Fixed and Discriminatory Pricing Strategies for Potential Switchgrass-to-Ethanol Conversion Facilities in Alabama." Biomass and Bioenergy 28(3), (2005): 295-306.

Hayk Khachatryan earned his M.A. in applied economics from Washington State University (WSU) in 2006. He is currently pursuing an interdisciplinary Ph.D. program (combining economics, marketing and environmental science/regional planning) at WSU, specializing in transport economics and marketing of biofuels, spatial econometrics and Geographic Information Systems.

Eric Jessup is an assistant professor in the School of Economic Sciences at Washington State University. His research focus and area of specialty is transportation economics and freight systems modeling. He is also co-principal investigator for the multi-year, statewide freight research and implementation project for the state of Washington, the Strategic Freight Transportation Analysis (SFTA) study.

Ken Casavant is a professor in the School of Economic Sciences at Washington State University. He has been conducting a transportation research program for almost 40 years in the area of transportation policy and marketing. He currently leads the Transportation Research Group, which conducts several million dollars of transportation economics and logistics research for state and national clients. 